\title{
PrÁticas METOdológICAS UTILIZADAS POR PESQUISADORES BRASILEIROS EM ESTUDOS DE ESTRATÉGIA
}

STRATEGY STUDIES: METHODOLOGICAL PRACTICES EMPLOYED BY BRAZILIAN RESEARCHERS

\author{
JULIO ERNESTO COLLA (juliocolla@ gmail.com) \\ JÚlio AdRIANo FERREIRA dos REIS \\ HEITOR TAKASHI KATO \\ PONTIFÍCIA UNIVERSIDADE CATÓliCA DO PARANÁ
}

\section{RESUMO}

O presente artigo busca verificar as práticas metodológicas utilizadas nos estudos brasileiros em estratégia. O presente estudo preocupa-se com o que os pesquisadores fazem em relação às opções metodológicas para atingirem os objetivos de suas pesquisas. A abordagem da presente pesquisa é predominantemente qualitativa, com suporte de estatística simplificada e possui caráter descritivo, pois busca expor características de determinada população ou de determinado fenômeno. Os dados da pesquisa são documentais, obtidos pela análise de 206 artigos apresentados na divisão de Estratégia em Organizações dos Anais do Encontro da Associação Nacional das Pós-Graduações em Administração (ANPAD), entre os anos de 2007 e 2010. Percebeu-se que a área de estudos em estratégia pode ser considerada em evolução com relação à complexidade metodológica. Os dados da pesquisa possibilitam inferir que um trabalho brasileiro em estratégia tipicamente pode ser representado pelas seguintes práticas metodológicas: abordagem qualitativa com utilização de dados primários, dados coletados por meio de questionário, tipo exploratório com perspectiva transversal.

Palavras-chave: procedimentos metodológicos em estratégia; pesquisa em estratégia; academia brasileira; estratégia. 


\section{ABSTRACT}

This article aims to investigate the methodological practices employed by Brazilian researchers studying strategy, with a focus on their choice of methodology to achieve the objectives of their research. The approach taken is largely qualitative, backed by straightforward statistical analysis. As such, this article is of a descriptive nature, with the intent to describe the characteristics of a given population or specific phenomenon. The research data consists solely of papers presented in the Strategy in Organizations Academic Division of the Annals of the Annual Meeting of the Brazilian Academy of Management/BAM (ANPAD) for 2007, 2008, 2009 and 2010. It was felt that the field of study is developing as regards methodological complexity. The research data suggest that a typically Brazilian Strategy study can be represented by the following methodological practices: a qualitative approach with the use of primary data, data collected through questionnaires, and practices of an exploratory nature with a temporal perspective of transversality.

Keywords: methodological procedures in strategy; research strategy; Brazilian Academy of Management/BAM; strategy.

\section{INTRODUÇÃO}

Os estudos que descrevem, explicam e analisam a academia, no geral, e a brasileira, em específico, vêm ganhando robustez nas duas últimas décadas, o que pode ser constatado pelo grande número de trabalhos não só em eventos específicos, mas também em periódicos. Da mesma forma que acontece com outras áreas do conhecimento, a análise dos estudos em Administração, no geral, e os estudos em Estratégia, em específico, ganharam notoriedade contemporânea. No Brasil, foi na década de 1990 que a publicação de balanços da produção acadêmica em administração começou a ganhar maior destaque (JABBOUR; SANTOS; BARBIERI, 2008; BERTERO; CALDAS; WOOD Jr., 1999; BERTERO; KEINERT, 1994; MACHADO-DA-SILVA; CUNHA; AMBONI, 1990).

Os últimos anos da pesquisa acadêmica no Brasil têm sido marcados por uma série de balanços retrospectivos que visam analisar a qualidade da produção nacional publicada (NASSIF; SILVA; ONO; BONTEMPO, 2009). O fenômeno do aumento de trabalhos que analisam a produção acadêmica tem relação direta com o avanço do número de 
programas de pós-graduação stricto senso, e sua consequente influência na ampliação dos canais de comunicação, notadamente os eventos e revistas científicas (GOMES; CORRÊA; DOMINGOS, 2010).

No ano de 2009, sob a égide dos eventos promovidos pela ANPAD, somente na área de Estratégia, foram apresentados três trabalhos no XXXIII EnANPAD com o intuito de analisar a produção acadêmica desta área, além de cinco no IV Encontro de Estudos em Estratégia. Também são encontrados trabalhos que analisam a produção acadêmica em Estratégia em periódicos nacionais e internacionais. No ano de 2010, somente no XXXIV Encontro da ANPAD foram apresentados dois trabalhos com o cunho de analisar a produção acadêmica em estratégia. A produção cientifica de uma área de conhecimento reflete o seu estado da arte e sua evolução (MELI, 2010).

Apesar de diversos artigos que se propuseram a analisar a academia nacional, não foram encontrados relatos específicos de estudos que tratassem das práticas metodológicas utilizadas nas pesquisas em Estratégia. Foi encontrado um texto sobre práticas metodológicas da academia que estudavam as publicações a respeito do empreendedorismo feminino, como no trabalho de Cassol, Silveira e Hoeltgebaum (2007).

Outra justificativa para o presente artigo é o fato de que os temas de interesse do evento analisado são transitórios, ou seja, são dinâmicos e renováveis (ANPAD, 2010). Essa condição de não perenidade apresenta a necessidade de apreciação do que foi produzido, sob pena de se perder a evolução metodológica da academia nacional, no geral, e de seus autores nas diversas áreas de estudo em estratégia. Assim, a presente pesquisa mostra-se relevante ao oferecer subsídios para pesquisados e estudiosos dos procedimentos metodológicos, visto que a prática da pesquisa apresenta-se em permanente discussão.

Este estudo trata, portanto, da análise da produção científica, visto que nesta inclui-se a produção de conhecimento por meio da pesquisa, que se entende pela busca sistemática, crítica e controlada de um maior conhecimento das relações existentes da realidade. Uma definição mais ampla de produção científica inclui trabalhos que possuem rigor científico no tratamento dos temas, incluindo-se, neste universo, monografias, dissertações, teses e artigos (LEITE FILHO, 2009). Diante do exposto, o presente artigo busca verificar as práticas metodológicas utilizadas no estudo da Estratégia no Brasil. Para atingir tal objetivo, ele foi subdividido em: levantar a filiação institucional dos pesquisadores, suas principais práticas metodológicas e bases teóricas de metodologia utilizada, bem como a busca da prática metodológica relacionada à área 
temática à qual o artigo pertence. Assim, esse estudo preocupa-se com o que os pesquisadores brasileiros fazem em termos metodológicos.

É importante salientar que não se pretende colocar em discussão, ou aquecer o embate sobre pesquisa qualitativa versus quantitativa ou, ainda, discussões sobre a existência de instrumento de coleta de dados ideal ou, ainda, qual o método mais adequado de análise dos dados coletados, pois a pretensão desse estudo é, exclusivamente, lançar um olhar sobre as práticas metodológicas utilizadas pelos pesquisadores em seus estudos.

Este artigo está subdividido em cinco seções: a primeira apresenta a introdução; a segunda seção apresenta o referencial teórico a respeito da pesquisa em Administração Estratégica; já a terceira seção apresenta o caminho metodológico percorrido; na quarta seção são apresentadas as análises da pesquisa; e, por fim, a quinta seção apresenta os principais achados deste trabalho, além de sugestões para novos e complementares trabalhos.

\section{REFERENCIAL TEÓRICO}

Apesar de ainda estar em fase de crescimento, a produção acadêmica em Administração no Brasil passou por profundas transformações, entre as quais se destaca seu significativo incremento quantitativo, principalmente durante a década de 1990. Tal crescimento pode ter uma vertente de explicação pela expansão dos cursos de pós-graduação em Administração, e outra pelo exercício de maior pressão da CAPES - Coordenadoria de Aperfeiçoamento do Ensino Superior, no sentido de estimular a produção acadêmica e sua divulgação sistemática em periódicos de excelência e abrangência nacional (JABBOUR; SANTOS; BARBIERI, 2008, BERTERO; CALDAS; WOOD Jr., 1999).

O escopo da pesquisa em Administração é amplo, e os tipos de fenômenos que os pesquisadores estudam estão crescendo e mudando rapidamente, ou seja, a pesquisa em Administração é verdadeiramente dinâmica, razão pela qual os pesquisadores estão constantemente estudando novas questões para pesquisa (HAIR; BABIN; MONEY; SAMOUEL, 2005). Desses estudos, decorre a publicação dos resultados das pesquisas, por meio de artigos científicos, que tem para o pesquisador o objetivo da divulgação de suas descobertas científicas, de proteger sua propriedade intelectual, bem como de trazer o reconhecimento de seus pares por meio da apresentação de seu caminho metodológico (SILVA; MENEZES; PINHEIRO, 2003; PREARO; ROMEIRO, 2010). 
Assim, acredita-se que, para a construção do conhecimento científico, é essencial o permanente diálogo entre diferentes pesquisadores, o que promoverá, em consequência, a troca de conhecimento entre autores, instituições e países (WALTER; LANZA; SATO; SILVA; BACH, 2010), porque a pesquisa científica é sustentada por formulação de problemas e adoção de técnicas e instrumentos de pesquisa (MORIKI; MARTINS, 2003). Tal argumentação é válida, pois para a compreensão de grande parte dos fenômenos organizacionais é necessário conhecimento intersubjetivo e compreensivo (GODOI; BANDEIRA-DE-MELLO; SILVA, 2006).

Diante do exposto, decorre a necessidade do entendimento de práticas metodológicas, visto que a discussão sobre ciência passa sempre pelo conhecimento da realidade (MINAYO, 1994). Por essas características, o campo científico, no geral, distingue-se dos demais pela imposição de uma forma regulada e organizada de competição, pelos constrangimentos lógicos e experimentais a que estão sujeitas as formas de conhecimento, bem como pela finalidade do conhecimento nele produzido (BARATA; GOLDBAUM, 2003).

Especificamente sobre o campo de estudos de estratégia, percebese que este tem sido marcado, ao longo de sua evolução, pelo dualismo entre prática e teoria. $\mathrm{O}$ embate deu origem a tendências caracterizadas por períodos de interesse parcial em torno de determinados aspectos característicos da complexidade desta área de estudos. Isso ocorre porque a área passa por constantes provocações e as pesquisas em estratégia, geralmente, são orientadas por questões de difícil investigação empírica, principalmente, àquelas que tratam da formação e implantação de estratégias e seu gerenciamento ao longo do tempo (BULGACOV; SOUZA; PROHMANN; COSER; BARANIUK, 2007; PETTIGREW, 1992; MINTZBERG; AHLSTRAND; LAMPEL, 2000).

Diante do exposto, estudos que tratam da avaliação do que é produzido cientificamente é desejado em função do crescimento exponencial da informação científica e tecnológica. Mesmo com a especialização das mídias, este tipo de análise presta um serviço de sintetização da produção intelectual e parece auxiliar no entendimento do que fora produzido (MATURANA, 2008). As questões técnicas e tecnológicas auxiliam na criação de conceitos, métodos e técnicas para a compreensão do mundo, das coisas, dos fenômenos, processos e das relações (MINAYO, 1994). 


\section{METODOLOGIA}

A abordagem da presente pesquisa é simultaneamente quantitativa e qualitativa, pois se busca aprofundar os conhecimentos sobre determinado assunto e permite analisar aspectos subjetivos, tais como percepções, compreensão do contexto da organização, significados compartilhados e a dinâmica das interações (CRESWELL; 2007; FLICK, 2004; MAY, 2004; VERGARA, 2000). Sendo assim, a análise qualitativa se torna a mais indicada quando o que se objetiva é a compreensão do fenômeno, de uma forma ampla e em sua complexidade (GODOY, 1995; RICHARDSON, 1985). A utilização de estatística como apoio à pesquisa qualitativa não a descaracteriza (TRIVIÑOS, 1987), mas, a complementa, dando mais suporte para a compreensão e a análise dos dados.

A presente pesquisa possui caráter descritivo, pois busca expor características de uma determinada população ou de determinado fenômeno (VERGARA, 2000, MALHOTRA, 2006), procurando descrever suas características, registrar, analisar e interpretar a natureza atual da realidade, com vistas ao aprimoramento de ideias (GIL, 1996). Portanto, o foco principal de estudos descritivos está no desejo de conhecer fatos e fenômenos de determinada realidade (TRIVIÑOS, 1987; CRESWELL, 2007; HAIR et al., 2005; GODOY, 1995).

Os dados da pesquisa são de origem documental, obtidos por meio da consulta nos Anais dos Encontros da ANPAD - ENANPAD, ocorridos nos anos de 2007, 2008 e 2010 no Rio de Janeiro e 2009 em São PauloSP. Tal encontro reúne 11 Divisões Acadêmicas, as quais agregam os Temas de Interesse associados. É válido o conhecimento de que as Divisões Acadêmicas são de natureza permanente ao passo que os Temas de Interesse são dinâmicos e renováveis. A população estudada é representada pelos artigos publicados na Divisão de Estratégia destes Encontros. Foram selecionados os artigos cujos autores declaram participar de um programa de pós-graduação. Ressalta-se que os artigos dos anos 2007, 2008 e 2009 foram enquadrados novamente, de acordo com os Temas de Interesse do evento de 2010.

A coleta dos dados aconteceu por meio da manipulação dos artigos (primeiramente por meio da leitura dos resumos, seguida da leitura da seção de metodologia e, quando não era possível a extração dos dados por meio desses procedimentos, foi efetuada a leitura completa do artigo) seguindo um roteiro pré-estabelecido assim constituído: Tema; Área; Código; Nome do artigo; Programa dos Pesquisadores; Universidade; Estado; Abordagem da Pesquisa - quantitativa, qualitativa ou mista; Tipo 
de coleta de dados - questionário, entrevista ou banco de dados; Dados primário ou secundário; Análise dos dados - análise de conteúdo, interpretativa, estatística descritiva ou análise fatorial exploratória; Tipo de trabalho - teórico-empírico ou ensaio; Tipo de estudo - exploratório, explicativo ou experimental; Nível de análise; Perspectiva temporal longitudinal ou transversal.

Para a presente pesquisa, foram utilizados somente artigos confeccionados por autores de um mesmo programa de pós-graduação, pois dessa forma acredita-se que se consiga um padrão de publicações que represente de forma mais efetiva os programas brasileiros, além de verificar a efetividade de publicações diretas dos programas de pósgraduação no Brasil. Assim reconhece-se que as características metodológicas da academia brasileira são representadas pela junção das práticas metodológicas de cada programa e os pesquisadores desses programas, respeitando suas particularidades e vocação em pesquisa. Todavia, outros caminhos metodológicos podem ser percorridos, tal como a possibilidade de eliminação das influências das instituições de ensino por meio de métodos estatísticos multivariados. É importante salientar que os artigos analisados não constam do referencial deste trabalho, visto que foram consultados como fontes de dados. Outro fato que se faz necessário esclarecer nessa fase do texto refere-se à supressão das tabelas explicativas, na seção de análise dos dados, pelo motivo de que extrapolaria o espaço disponível para publicação além de se tornar cansativo para os leitores. Desde já, os autores colocam-se à disposição para o envio das tabelas e quadros, bem como das planilhas eletrônicas utilizadas que serviram de base para as análises apresentadas.

Tabela 1: Trabalhos apresentados e analisados por ano (2007-2010)

\begin{tabular}{ccccc}
\hline Ano & Apresentados & Analisados & \% Analisado/ano & \% Analisado/Total \\
\hline 2010 & 123 & 45 & 36,59 & 21,8 \\
\hline 2009 & 130 & 59 & 45,38 & 28,6 \\
\hline 2008 & 109 & 48 & 44,04 & 29,8 \\
\hline 2007 & 104 & 54 & 51,92 & 26,2 \\
\hline Total & 466 & 206 & & 100 \\
\hline
\end{tabular}

A divisão acadêmica de Estratégia em Organizações, no ano de 2007, apresentou 104 artigos, dos quais, após filtragem, foram analisados 54; em 2008 foram apresentados 109 artigos, dos quais 48 atendiam aos critérios da pesquisa; na edição de 2009 foram apresentados 130 artigos, e 59 atendiam aos critérios da pesquisa; e por fim, no ano de 2010, dos 123 trabalhos apresentados, foram analisados 45. A Tabela 1 apresenta os 
percentuais dos artigos analisados por ano e sua representatividade no total de artigos analisados.

Tabela 2: Artigos analisados por área e por ano

\begin{tabular}{|c|c|c|c|c|c|c|c|}
\hline \multirow{2}{*}{\multicolumn{2}{|c|}{ Tema }} & \multicolumn{4}{|c|}{ Ano } & \multirow{2}{*}{ Total } & \multirow{2}{*}{$\begin{array}{l}\text { \% do } \\
\text { Total }\end{array}$} \\
\hline & & 2010 & 2009 & 2008 & 2007 & & \\
\hline \multirow{2}{*}{$\begin{array}{l}\text { Ambiente, Estratégia e } \\
\text { Instituições }\end{array}$} & Quant. & 2 & 6 & 3 & 6 & 17 & \multirow{2}{*}{8,25} \\
\hline & $\%$ tema & 11,76 & 35,29 & 17,65 & 35,29 & 100 & \\
\hline \multirow{2}{*}{$\begin{array}{c}\text { Cenários, Diretrizes e } \\
\text { Planejamento } \\
\text { Estratégico }\end{array}$} & Quant. & 1 & 1 & 2 & 1 & 5 & \multirow{2}{*}{2,43} \\
\hline & $\%$ tema & 20 & 20 & 40 & 20 & 100 & \\
\hline \multirow{2}{*}{$\begin{array}{l}\text { Conteúdo, Processo e } \\
\text { Práticas Estratégicas }\end{array}$} & Quant. & 5 & 6 & 3 & 9 & 23 & \multirow{2}{*}{11,17} \\
\hline & $\%$ tema & 21,74 & 26,09 & 13,04 & 39,13 & 100 & \\
\hline \multirow{2}{*}{$\begin{array}{c}\text { Estratégia Competitiva e } \\
\text { Corporativa }\end{array}$} & Quant. & 13 & 6 & 4 & 4 & 27 & \multirow{2}{*}{3,11} \\
\hline & $\%$ tema & 48,15 & 22,22 & 14,81 & 14,81 & 100 & \\
\hline \multirow{2}{*}{$\begin{array}{c}\text { Estratégia e } \\
\text { Sustentabilidade } \\
\text { Socioambiental }\end{array}$} & Quant. & 6 & 8 & 1 & 0 & 15 & \multirow[b]{2}{*}{7,28} \\
\hline & $\%$ tema & 40 & 53,33 & 6,67 & - & 100 & \\
\hline \multirow{2}{*}{$\begin{array}{c}\text { Estratégia, } \\
\text { Empreendedorismo e } \\
\text { Desenvolvimento }\end{array}$} & Quant. & 1 & 6 & 7 & 7 & 21 & \multirow{2}{*}{10,19} \\
\hline & $\%$ tema & 4,76 & 28,57 & 33,33 & 33,33 & 100 & \\
\hline \multirow{3}{*}{$\begin{array}{c}\text { Estratégias } \\
\text { Colaborativas, Alianças, } \\
\text { Fusões e Aquisições }\end{array}$} & Quant. & 3 & 8 & 10 & 9 & 30 & \multirow{3}{*}{14,56} \\
\hline & $\%$ tema & 10 & 26,67 & 33,33 & 30 & 100 & \\
\hline & $\%$ total & 1,46 & 3,88 & 4,85 & 4,37 & 14,56 & \\
\hline \multirow{2}{*}{ Gestão Internacional } & Quant. & 0 & 4 & 4 & 5 & 13 & \multirow{2}{*}{6,31} \\
\hline & $\%$ tema & - & 30,77 & 30,77 & 38,46 & 100 & \\
\hline \multirow{2}{*}{$\begin{array}{c}\text { Gestão, Mensuração e } \\
\text { Desempenho } \\
\text { Organizacional }\end{array}$} & Quant. & 2 & 5 & 5 & 5 & 17 & \multirow[b]{2}{*}{8,25} \\
\hline & $\%$ tema & 11,76 & 29,41 & 29,41 & 29,41 & 100 & \\
\hline \multirow{2}{*}{$\begin{array}{c}\text { Governo, Ações de Não } \\
\text { Mercado e Perspectivas } \\
\text { Críticas }\end{array}$} & Quant. & 4 & 0 & 0 & 0 & 4 & \multirow[b]{2}{*}{1,94} \\
\hline & $\%$ tema & 100 & 0 & 0 & 0 & 100 & \\
\hline \multirow{2}{*}{$\begin{array}{c}\text { Internacionalização de } \\
\text { Empresas }\end{array}$} & Quant. & 1 & 1 & 1 & 1 & 4 & \multirow{2}{*}{1,94} \\
\hline & $\%$ tema & 25 & 25 & 25 & 25 & 100 & \\
\hline \multirow{2}{*}{ Teorias da Estratégia } & Quant. & 5 & 6 & 6 & 5 & 22 & \multirow{2}{*}{10,68} \\
\hline & $\%$ tema & 22,73 & 27,27 & 27,27 & 22,73 & 100 & \\
\hline \multirow{2}{*}{ Temas Livres } & Quant. & 2 & 2 & 2 & 2 & 8 & \multirow{2}{*}{3,88} \\
\hline & $\%$ tema & 25 & 25 & 25 & 25 & 100 & \\
\hline Total & Quant. & 45 & 59 & 48 & 54 & 206 & \\
\hline 10 tal & $\%$ tema & 21,84 & 28,64 & 23,30 & 26,21 & 100 & \\
\hline
\end{tabular}

* Nota: houve reenquadramento dos artigos dos anos 2007, 2008 e 2009 de acordo com os Temas de Interesse do evento de 2010.

A Tabela 2 apresenta o total de artigos analisados, por áreas temáticas e por anos bem como as quantidades e percentuais de representatividade de artigos de cada área. É possível observar na Tabela 
que não houve análise de artigos pertencentes ao tema Estratégia e Sustentabilidade Socioambiental no ano de 2007, bem como em Governo, Ações de Não Mercado e Perspectivas Críticas nos anos de 2007 a 2009. $\mathrm{O}$ tema com maior percentual de trabalhos analisados foi o tema Estratégias Colaborativas, Alianças, Fusões e Aquisições com 14,56\%, (30 artigos) dos artigos analisados, seguido do tema Conteúdo, Processo e Práticas Estratégicas com 11,17\% (23) do total dos artigos dessa divisão. Com relação ao tema com maior número de artigos analisados por ano, é válido afirmar que, em 2007, o tema Conteúdo, Processo e Práticas Estratégicas e Estratégias Colaborativas, Alianças, Fusões e Aquisições com nove artigos $(16,67 \%)$ do total do ano representam os dois temas com maior número de artigos analisados.

No ano de 2008, o tema Estratégias Colaborativas, Alianças, Fusões e Aquisições com dez artigos (20,83\%) e Estratégia, Empreendedorismo e Desenvolvimento com sete artigos (14,58\%) representam os dois temas com maior número de trabalhos analisados nesse ano.

Os temas Estratégia, Empreendedorismo e Desenvolvimento e Estratégias Colaborativas, Alianças, Fusões e Aquisições com oito artigos $(13,56 \%)$ em 2009, representam os temas com maior número de artigos analisados.

Em 2010, o tema Estratégia Competitiva e Corporativa apresentou o maior índice de representação com 48,15\% do total de artigos analisados e Estratégia e Sustentabilidade Socioambiental, com seis artigos, foram uma das seções que mais contribuiu com os artigos analisados. Ainda, quanto ao ano de 2010, é importante ressaltar que algumas áreas tiveram a apresentação de artigos bastante reduzida, como é o caso de Ambiente, Estratégia e Instituições, que caíram de seis artigos no ano de 2009 para dois artigos em 2010 e Estratégia, Empreendedorismo e Desenvolvimento que apresentou seis artigos em 2009 e apenas um artigo em 2010.

\section{ANÁLISE DOS DADOS}

O início da apresentação e análise dos dados acontece com a apresentação da distribuição dos artigos apresentados por programas de pós-graduação e os temas a que estes pertenciam. A análise dos resultados está subdividida em três partes. A primeira apresenta os programas com maior produção dentro dos critérios estabelecidos; a segunda parte é constituída 
pelas posturas metodológicas dos Temas de Interesse do ENANPAD; e, por fim, são realizadas inferências dos artigos que caracterizam as áreas temáticas.

A Tabela 3 mostra a produção acadêmica dos programas de pesquisa que mais produziram individualmente na Divisão de Estratégia Organizacional.

Tabela 3: Quantidade de artigos analisados por programas (2007-2010)

\begin{tabular}{llcccccc}
\hline \multirow{2}{*}{ Ordem } & \multirow{6}{*}{ Programa } & \multicolumn{7}{c}{ Ano } & \multirow{2}{*}{ Q Total } & \multirow{2}{*}{ \% Total } \\
\cline { 3 - 6 } & & 10 & 09 & 08 & 07 & & \\
\cline { 2 - 6 } & & $\mathrm{Q}$ & $\mathrm{Q}$ & $\mathrm{Q}$ & $\mathrm{Q}$ & & 12,14 \\
\hline 1 & PPGAE/Mackenzie & 7 & 10 & 4 & 4 & 25 & 7,3 \\
\hline 2 & PPAD/PUC-PR & 7 & 3 & 4 & 1 & 15 & 6,79 \\
\hline 3 & PPGAdm/UNISINOS & 3 & 4 & 3 & 4 & 14 & 5,83 \\
\hline 4 & EAESP/FGV & 1 & 2 & 1 & 8 & 12 & 4,37 \\
\hline 5 & PPGA/USP & 3 & 1 & 1 & 4 & 9 & 3,9 \\
\hline 6 & CEPPAD/UFPR & 0 & 3 & 3 & 2 & 8 & 3,9 \\
\hline 7 & PROPAD/UFPE & 2 & 1 & 1 & 4 & 8 & 3,4 \\
\hline 8 & CMAAd/UECE & 2 & 3 & 2 & 0 & 7 & 3,4 \\
\hline 9 & COPPEAD/UFRJ & 0 & 3 & 3 & 1 & 7 & 34,43 \\
\hline 10 & PPGAT/UNIVALI & 1 & 1 & 3 & 2 & 7 & 100 \\
\hline Demais & & 19 & 28 & 23 & 24 & 94 & 54 \\
\hline Total & & 45 & 59 & 48 & 54 & 206 & \\
\hline
\end{tabular}

De acordo com a Tabela 3, merecem destaque por apresentarem uma produção individual significativa no período analisado, os programas PPGAE/Mackenzie com 25 artigos apresentados na Divisão Acadêmica de Estratégia, o que representa $12,14 \%$ do total de artigos analisados; PPAD/PUC-PR, com 15 artigos apresentados com autores de seu programa, o que representa $7,3 \% \%$ do total de artigos; PPGAdm/UNISINOS com 14 artigos $6,79 \%$ do total analisado; EAESP/FGV com 12 artigos, representando 5,83\% do total de artigos analisados; PPGA/USP com nove artigos representando $4,37 \%$ dos artigos analisados; e CEPPAD/UFPR e PROPAD/UFPE com oito artigos cada programa, o que representa 3,9\% dos artigos analisados. Ao todo foram encontrados $56 \mathrm{com}$ apresentação de artigos.

Os demais programas que constam da Tabela 3 apresentaram quantidades menores que sete trabalhos apresentados. É importante ressaltar novamente que os artigos analisados são somente os que apresentam autoria de um mesmo programa de pesquisa. Assim, a configuração aqui obtida representa a academia brasileira não considerando as coautorias. 
Ao serem analisadas as abordagens metodológicas, que é um objetivo decorrente da presente pesquisa, pode-se perceber uma predominância de artigos que adotam métodos qualitativos com 127 trabalhos, o que representa $61,65 \%$ do total analisado na Divisão de Estratégia em Organizações. A abordagem quantitativa foi usada por 64 trabalhos ou $31,07 \%$ do total e, por fim, a abordagem mista, que apresenta etapas qualitativas e quantitativas, com 15 trabalhos representando, assim, $7,28 \%$ do total de artigos analisados.

Tabela 3: Predomínios das abordagens de pesquisa

\begin{tabular}{ccc}
\hline Item analisado & Predomínio & $\begin{array}{c}\text { Percentuais } \\
\text { do item (\%) }\end{array}$ \\
\hline $\begin{array}{c}\text { Divisão de Estratégia } \\
\text { Organizacional }\end{array}$ & Qualitativo & 61,6 \\
\hline $\begin{array}{c}\text { Internacionalidade de Empresas } \\
\text { e Estratégia e Sustentabilidade } \\
\text { Organizacional }\end{array}$ & $\begin{array}{c}\text { Maior utilização da } \\
\text { abordagem qualitativa }\end{array}$ & 80 \\
\hline $\begin{array}{c}\text { Ambiente, Estratégia e } \\
\text { Instituições }\end{array}$ & $\begin{array}{c}\text { Maior utilização da } \\
\text { abordagem quantitativa }\end{array}$ & 47 \\
\hline Tema Livre & $\begin{array}{c}\text { Maior utilização da } \\
\text { abordagem mista }\end{array}$ & 25 \\
\hline
\end{tabular}

A Tabela 4 apresenta a síntese dos predomínios metodológicos encontrados com relação ao tipo de abordagem de pesquisa utilizada pelos autores.

Ainda com relação à abordagem, percebe-se uma tendência a estudos qualitativos em todos os temas e salienta-se que $80 \%$ dos artigos dos temas Internacionalização de Empresas e Estratégia e Sustentabilidade Socioambiental usaram métodos qualitativos. O tema Governo, Ações de Não Mercado e Perspectivas Críticas teve $75 \%$ dos seus artigos com abordagem qualitativa e o tema Conteúdo, Processo e Práticas Estratégicas com 73,91\%. As áreas de pesquisas com menor percentual de artigos qualitativos foram Ambiente, Estratégia e Instituições e Gestão, Mensuração e Desempenho Organizacional com $52,94 \%$ dos artigos.

A abordagem qualitativa aparece nos temas Ambiente, Estratégia e Instituições, 47,06\% dos trabalhos; e Gestão, Mensuração e Desempenho Organizacional com 41,18\% dos trabalhos. É destaque ainda, a Teoria da Estratégia, com 40,91\%. Estratégia Competitiva e Corporativa com 40,74\% e Cenários, Diretrizes e Planejamento Estratégico com $40 \%$ dos artigos são os merecedores de destaque quando o assunto é a abordagem 
quantitativa, apesar de não haver um tema com predomínio desse tipo de abordagem de pesquisa.

Os artigos do Tema Livre apresentaram o maior percentual de trabalhos com a abordagem mista (25\%), seguido do tema Estratégia, Empreendedorismo e Desenvolvimento com 14,29\% dos trabalhos, e da área que estuda Estratégias Colaborativas, Alianças, Fusões e Aquisições, que apresentou $13,33 \%$.

No que se refere às fontes dos dados trabalhados durante o período estudado, sintetizados na Tabela 5, foi encontrado que a divisão de Estratégia em Organizações caracteriza-se pela predominância de manipulação de dados primários, pois dos 206 artigos analisados 104, ou seja, 50,49\% do total examinado utilizavam este tipo de dados; 40 artigos lidaram com dados secundários, o que corresponde a 19,42\% do total. Ainda foram encontrados 19 artigos, 9,22\% do total, que trabalharam com os dois tipos de dados e, por fim, foram encontrados 43 artigos, ou $20,87 \%$ do total dos trabalhos, que não utilizaram nenhum tipo específico de dados, pois foram classificados como ensaios teóricos. É válido salientar que os ensaios teóricos também possuem fonte de dados, porém fogem do escopo desse trabalho.

Tabela 4: Fonte dos dados utilizados

\begin{tabular}{ccc}
\hline Item analisado & Predomínio & $\begin{array}{c}\text { Percentuais } \\
\text { do item (\%) }\end{array}$ \\
\hline $\begin{array}{c}\text { Divisão de Estratégia } \\
\text { Organizacional }\end{array}$ & Dados primários & 50,4 \\
\hline $\begin{array}{c}\text { Conteúdo, Processo e Práticas } \\
\text { Estratégicas e Teorias da } \\
\text { Estratégia }\end{array}$ & $\begin{array}{c}\text { Maior utilização dos } \\
\text { dados primários }\end{array}$ & 69,5 \\
\hline $\begin{array}{c}\text { Governo, Ações de Não } \\
\text { Mercado e Perspectivas Críticas }\end{array}$ & $\begin{array}{c}\text { Maior utilização da } \\
\text { abordagem quantitativa }\end{array}$ & 50 \\
\hline $\begin{array}{c}\text { Internacionalização de } \\
\text { Empresas }\end{array}$ & $\begin{array}{c}\text { Maior utilização da } \\
\text { abordagem mista }\end{array}$ & 25 \\
\hline
\end{tabular}

A tipologia de dados utilizados nos artigos analisados, entre aos temas de interesse da Divisão de Estratégia Organizacional do EnANPAD, mostra que os dados primários foram mais utilizados nos trabalhos que estudaram Conteúdo, Processo e Práticas Estratégicas, com $69,57 \%$ dos trabalhos, seguido dos trabalhos sobre Teorias da Estratégia, com $68,18 \%$. Em terceiro lugar na quantidade de trabalhos que utilizam os dados primários está o tema Estratégia, Empreendedorismo e Desenvolvimento, com 66,67\%, seguido dos trabalhos acerca de Estratégia Competitiva e Corporativa que apresentou 55,56\% dos 
trabalhos analisados. A utilização de dados primários foi fortemente encontrada, com mais de $50 \%$ das pesquisas publicadas nas áreas temáticas de Estratégia Colaborativa, Alianças, Fusões e Aquisições e de Governo, Ações de Não Mercado e Perspectivas Críticas.

Os trabalhos a respeito de Governo, Ações de Não Mercado e Perspectivas Críticas foi o tema que mais utilizou os dados secundários (50\%) para a confecção dos trabalhos, seguido de Cenários, Diretrizes e Planejamento Estratégico com $40 \%$ dos trabalhos. As demais áreas temáticas utilizaram dados secundários em menos de $40 \%$ dos trabalhos analisados. Quando se verifica a utilização de dados primários e secundários como origem dos dados, o tema Internacionalização de Empresas foi o que apresentou maior índice percentual entre as áreas estudadas, com $25 \%$ dos trabalhos desse tema. Outro tema que merece destaque na utilização dessa abordagem mista é o tema Ambiente, Estratégia e Instituições com 17,65\% dos artigos.

Tabela 5: Fonte de Coleta de Dados

\begin{tabular}{ccc}
\hline Item analisado & Predomínio & $\begin{array}{c}\text { Percentuais } \\
\text { do item }(\%)\end{array}$ \\
\hline $\begin{array}{c}\text { Divisão de Estratégia } \\
\text { Organizacional }\end{array}$ & Questionário & 19,9 \\
\hline $\begin{array}{c}\text { Conteúdo, Processo e } \\
\text { Práticas Estratégicas }\end{array}$ & $\begin{array}{c}\text { Entrevista não } \\
\text { estruturada }\end{array}$ & 33,3 \\
\hline $\begin{array}{c}\text { Estratégia, Ambiente e } \\
\text { Instituições }\end{array}$ & Base de dados & 17,6 \\
\hline $\begin{array}{c}\text { Conteúdo, Processo e } \\
\text { Práticas Estratégicas }\end{array}$ & $\begin{array}{c}\text { Entrevista } \\
\text { semiestruturada }\end{array}$ & 17,9 \\
\hline $\begin{array}{c}\text { Estratégias } \\
\text { Colaborativas, Alianças, } \\
\text { Fusões e Aquisiçóes }\end{array}$ & $\begin{array}{c}\text { Múltiplas fontes } \\
\text { de dados }\end{array}$ & 25 \\
\hline Teoria da Estratégia & Questionário & 31,8 \\
\hline $\begin{array}{c}\text { Estratégia Competitiva e } \\
\text { Corporativa }\end{array}$ & Documentos & 33,3 \\
\hline $\begin{array}{c}\text { Internacionalização de } \\
\text { Empresas }\end{array}$ & $\begin{array}{c}\text { Observação } \\
\text { participante }\end{array}$ & 25 \\
\hline
\end{tabular}

A Tabela 6 apresenta os dados no que tange à fonte de coleta de dados. Independentemente de esses dados terem origem primária ou secundária, ficou evidenciado que 15 artigos, 7,28\% do total, utilizaram a entrevista não estruturada; 34 artigos, ou seja, 16,50\% utilizaram alguma base de dados como fonte para a pesquisa (as bases de dados consideradas são aquelas em que os autores conseguem os dados para serem utilizados diretamente, por exemplo, IBGE e Economática); 39 artigos, ou 18,93\% 
usaram a entrevista semiestruturada como fonte de coleta dos dados; 24 artigos ou $11,65 \%$ usaram maneiras múltiplas para a coleta de dados, ou seja, usaram mais de uma técnica; 41 artigos, ou 19,90\% do total utilizam o questionário, sendo importante ressaltar que essa forma de coleta de dados foi a mais utilizada nos artigos analisados. Também foram encontrados nove artigos, ou $4,37 \%$ do total analisado, que utilizaram documentos como instrumento de coleta de dados, entendendo-se por documentos algum tipo de instrumento de coleta criado pelos pesquisadores. A observação participante foi utilizada como coleta de dados para apenas um artigo.

Quando confrontadas a forma de coleta dos dados com as áreas temáticas do evento, no período analisado, houve predominância da utilização de entrevista não estruturada nos trabalhos que pesquisam Conteúdo, Processo e Práticas Estratégicas (33,33\%), seguida dos trabalhos de Estratégia Competitiva e Corporativa (20\%). Também foram encontrados trabalhos dos temas Estratégias Colaborativas, Alianças, Fusões e Aquisições e Teorias da Estratégia (13,33\%). Essas três áreas de estudo são as que representam os temas que utilizaram esse tipo de fonte de coleta de dados.

O tema Estratégia, Ambiente e Instituições foi o que mais utilizou a base de dados como meio de coleta de dados, representando 17,65\% dos trabalhos. O tema Estratégia, Ambiente e Instituições também representou um percentual elevado de utilização de banco de dados como fonte de coleta dos dados. Com relação à entrevista semiestruturada, os trabalhos que tratam do Conteúdo, Processo e Práticas Estratégicas apresentaram maior utilização desse instrumento de coleta de dados, com 17,95\% dos trabalhos, que utilizaram essa forma de coleta dos dados. A área de estudos com maior percentual de trabalhos, que utilizou a entrevista semiestruturada foi Governo, Ações de Não Mercado e Perspectivas Críticas, com aproximadamente $50 \%$ utilizando esse instrumento.

Os trabalhos que estudam as Estratégias Colaborativas, Alianças, Fusões e Aquisições representam $25 \%$ dos trabalhos que utilizaram meios múltiplos de coleta de dados. Em relação à maior utilização percentual em uma área de estudo, os trabalhos sobre Teoria da Estratégia representam o tema de estudos que mais utilizou essa forma de coleta de dados. $\mathrm{O}$ questionário, maior forma de coleta de dados entre os trabalhos analisados, teve sua maior utilização nos trabalhos que estudavam a Estratégia Competitiva e Corporativa, com 19,51\% dos trabalhos que usaram essa forma de coleta. O tema que mais utilizou o questionário como fonte de coleta de dados foi o tema Teoria da Estratégia, com 
$31,82 \%$ dos trabalhos dessa área. Documentos como fontes de dados foram utilizados apenas pelo tema Estratégia Competitiva e Corporativa, com 33,33\% dos trabalhos, que usaram essa forma de coleta de dados. Outra forma de coleta de dados, a observação participante foi utilizada apenas por um trabalho no tema Internacionalização de Empresas.

Nos trabalhos apresentados na Divisão de Estratégia do ENANPAD, no período estudado, foi encontrado que 37,86\% (78 artigos) foram exploratórios, $29,61 \%$ (61 artigos) foram explicativos e 32,04\%, (66 artigos) descritivos. Também foi encontrado um estudo experimental, confirmando ser um método pouco usual na área. É importante ressaltar a grande semelhança nos percentuais de cada tipo de pesquisa encontrado, ou seja, um equilíbrio quanto à tipologia dos estudos realizados nos trabalhos analisados. A Tabela 7 sintetiza as principais informações encontradas com relação à tipologia das pesquisas.

Tabela 6: Tipologia da Pesquisa

\begin{tabular}{ccc}
\hline Item analisado & Predomínio & $\begin{array}{c}\text { Percentuais } \\
\text { do item (\%) }\end{array}$ \\
\hline $\begin{array}{c}\text { Divisão de Estratégia } \\
\text { Organizacional }\end{array}$ & Exploratório & 37,8 \\
\hline $\begin{array}{c}\text { Estratégia Competitiva e } \\
\text { Corporativa }\end{array}$ & Pesquisa exploratória & 75 \\
\hline $\begin{array}{c}\text { Estratégias Colaborativas, } \\
\text { Alianças, Fusões e Aquisições }\end{array}$ & Pesquisa explicativa & 47,1 \\
\hline $\begin{array}{c}\text { Estratégia Competitiva e } \\
\text { Corporativa e Conteúdo, } \\
\text { Processo e Práticas Estratégicas }\end{array}$ & Pesquisa descritiva & 50 \\
\hline
\end{tabular}

O tipo exploratório e o descritivo foram utilizados pelos pesquisadores de todos os temas. As pesquisas exploratórias foram mais empregadas nos trabalhos que tratam de Estratégia Competitiva e Corporativa. Com relação ao tema que mais as utilizou em termos percentuais foram encontrados os trabalhos que tratam de Governo, Ações de Não Mercado e Perspectiva Crítica, com $75 \%$ dos trabalhos sobre o tema com essa característica de pesquisa, seguido do tema Cenários, Diretrizes e Planejamento Estratégico, com 60\% dos trabalhos na área com características exploratórias.

No tema Estratégias Colaborativas, Alianças, Fusões e Aquisições, o tipo de pesquisa mais encontrado foi o explicativo. O tema que mais utilizou, proporcionalmente, esse tipo de pesquisa foi Ambiente, Estratégia e Instituições (47,06\% de seus trabalhos), seguido do tema Gestão Internacional $(38,46 \%)$. 
As pesquisas descritivas foram encontradas em todas as áreas temáticas, com maior utilização nos temas Estratégia Competitiva e Corporativa e Conteúdo, Processo e Práticas Estratégicas. Com relação à maior proporcionalidade dos artigos em relação às áreas temáticas que tratam de Temas Livres, com 50\% das pesquisas, seguido da temática Ambiente, Estratégia e Instituições com 41,18\% dos trabalhos.

Sob o aspecto da temporalidade, os estudos tiveram um número de 94, ou $45,63 \%$ do total classificados como longitudinais e 112 , ou $54,37 \%$ dos artigos analisados classificados como transversais. A Tabela 8 auxilia o entendimento da classificação de temporalidade, de acordo com a área temática em que o artigo está enquadrado.

Tabela 8: Temporalidade dos trabalhos

\begin{tabular}{|c|c|c|c|c|}
\hline \multirow{2}{*}{ Temas } & & \multicolumn{2}{|c|}{ Temporalidade } & \multirow{2}{*}{ Total } \\
\hline & & Longitudinal & Transversal & \\
\hline \multirow{2}{*}{ Ambiente, Estratégia e Instituições } & Quant. & 11 & 4 & 15 \\
\hline & $\%$ Tema & 73,3 & 26,6 & 100 \\
\hline \multirow{2}{*}{$\begin{array}{l}\text { Cenários, Diretrizes e Planejamento } \\
\text { Estratégico }\end{array}$} & Quant. & 2 & 2 & 4 \\
\hline & $\%$ Tema & 50 & 50 & 100 \\
\hline \multirow{2}{*}{$\begin{array}{c}\text { Conteúdo, Processo e Práticas } \\
\text { Estratégicas }\end{array}$} & Quant. & 13 & 5 & 18 \\
\hline & $\%$ Tema & 72,2 & 27,7 & 100 \\
\hline \multirow{2}{*}{$\begin{array}{l}\text { Estratégia Competitiva e } \\
\text { Corporativa }\end{array}$} & Quant. & 6 & 8 & 14 \\
\hline & $\%$ Tema & 42,8 & 57,1 & 100 \\
\hline \multirow{2}{*}{$\begin{array}{l}\text { Estratégia e Sustentabilidade } \\
\text { Socioambiental }\end{array}$} & Quant. & 7 & 2 & 9 \\
\hline & $\%$ Tema & 77,7 & 22,2 & 100 \\
\hline \multirow{2}{*}{$\begin{array}{l}\text { Estratégia, Empreendedorismo e } \\
\text { Desenvolvimento }\end{array}$} & Quant. & 2 & 18 & 20 \\
\hline & $\%$ Tema & 10 & 90 & 100 \\
\hline \multirow{2}{*}{$\begin{array}{c}\text { Estratégias Colaborativas, Alianças, } \\
\text { Fusões e Aquisições }\end{array}$} & Quant. & 8 & 19 & 27 \\
\hline & $\%$ Tema & 29,6 & 70,3 & 100 \\
\hline \multirow{2}{*}{ Gestão Internacional } & Quant. & 8 & 5 & 13 \\
\hline & $\%$ Tema & 61,5 & 38,4 & 100 \\
\hline \multirow{2}{*}{$\begin{array}{l}\text { Gestão, Mensuração e Desempenho } \\
\text { Organizacional }\end{array}$} & Quant. & 6 & 9 & 15 \\
\hline & $\%$ Tema & 40 & 60 & 100 \\
\hline \multirow{2}{*}{$\begin{array}{c}\text { Governo, Ações de Não Mercado e } \\
\text { Perspectivas Críticas }\end{array}$} & Quant. & 2 & 1 & 3 \\
\hline & $\%$ Tema & 66,6 & 33,3 & 100 \\
\hline \multirow{2}{*}{ Internacionalização de Empresas } & Quant. & 6 & 11 & 17 \\
\hline & $\%$ Tema & 35,2 & 64,7 & 100 \\
\hline \multirow{2}{*}{ Teorias da Estratégia } & Quant. & 4 & 1 & 5 \\
\hline & $\%$ Tema & 80 & 20 & 100 \\
\hline \multirow{2}{*}{ Temas Livres } & Quant. & 0 & 1 & 1 \\
\hline & $\%$ Tema & 0 & 100 & 100 \\
\hline \multirow{2}{*}{ Total } & Quant. & 75 & 86 & 161 \\
\hline & $\%$ Tema & 46,5 & 53,4 & 100 \\
\hline
\end{tabular}


Os estudos longitudinais e transversais foram usados pelos pesquisadores de todas as áreas temáticas. Na divisão estudada há predomínio dos estudos transversais, com 54,37\% dos trabalhos apresentados. O tema Ambiente, Estratégia foi o que mais utilizou os estudos longitudinais. Quanto aos estudos transversais, estes foram mais utilizados por pesquisadores que estudam Estratégia, Empreendedorismo e Desenvolvimento, com 90,48\% dos artigos dessa área temática.

É possível então inferir o trabalho típico da Divisão de Estratégia Organizacional apresentado nos EnANPADs, que pode ser representado pelas seguintes práticas metodológicas: abordagem qualitativa com utilização de dados primários, dados coletados por meio de questionário, tipo exploratório com perspectiva temporal de transversalidade.

Os trabalhos dos temas de interesse podem ser assim caracterizados: com relação ao tema Ambiente, Estratégia e Instituições, o artigo típico da área possui abordagem qualitativa, podendo utilizar tanto dados primários quanto secundários, com dados coletados em base de dados, tipo explicativo com temporalidade longitudinal. As pesquisas apresentadas na área temática Cenários, Diretrizes e Planejamento Estratégico podem ser descritas como as que utilizam abordagem qualitativa, com utilização de dados secundários, tipo exploratório e com perspectiva temporal transversal.

O tema Conteúdo, Processo e Práticas Estratégicas tem em seus trabalhos a característica da utilização da abordagem qualitativa, utilização de dados primários coletados por meio de entrevistas semiestruturadas, tipo exploratório e temporalidade longitudinal. A área de Estratégia Competitiva e Corporativa pode ser representada por trabalhos qualitativos, tipo exploratório e perspectiva temporal transversal.

A caracterização de um artigo típico da área de Estratégia e Sustentabilidade Socioambiental possui os seguintes atributos metodológicos: abordagem qualitativa, dados tanto primários quanto secundários, tipo exploratório e com temporalidade longitudinal. Já os trabalhos de Estratégia, Empreendedorismo e Desenvolvimento possuem as seguintes características: abordagem qualitativa com dados primários obtidos por meio de entrevistas semiestruturadas e questionários, tipo descritivo e temporalidade transversal. Com relação aos trabalhos de tema Estratégias Colaborativas, Alianças, Fusões e Aquisições, pode-se particularizá-los como tendo abordagem qualitativa, utilização de dados primários, dados coletados por meio de entrevistas semiestruturadas e 
múltiplos meios. Ainda possuem as características de tipificação explicativa e temporalidade transversal.

$\mathrm{O}$ artigo que caracteriza o tema de Gestão Internacional possui abordagem qualitativa com utilização de dados primários coletados por meio de fontes múltiplas, é tipicamente explicativo e longitudinal. Com relação ao tema Gestão, Mensuração e Desempenho Organizacional, pode-se individualizar um artigo que tenha a abordagem qualitativa, com relação ao tipo de pesquisa, é exploratório e, em relação ao tempo, é transversal. Os artigos do tema Governo, Ações de Não Mercado e Perspectivas Críticas podem ser exemplificados por meio da utilização de abordagem qualitativa, com utilização de dados tanto primários quanto secundários. Os dados primários utilizados são usualmente coletados por meio de entrevistas semiestruturadas e tipicamente exploratórios. Com relação à temporalidade, podem ser tanto longitudinal quanto transversal.

Os estudos a respeito da Internacionalização de Empresas podem ser reconhecidos como aqueles que utilizam a abordagem qualitativa, dados tanto primários quanto secundários. Os dados primários são coletados por meio de observação participante e com tipologia exploratória e temporalidade tanto longitudinal quanto transversal. Os artigos do tema Teorias da Estratégia podem ser caracterizados como tendo a abordagem qualitativa, utilizam dados primários, originários de entrevista semiestruturadas, tipicamente exploratórios e com temporalidade tanto transversal quanto longitudinal. Os artigos dos Temas Livres apresentam características de abordagem qualitativa, com utilização de dados secundários originários de bancos de dados. Esses estudos são tipicamente exploratórios e descritivos com temporalidade tanto longitudinal quanto transversal.

\section{CONSIDERAÇõES FinAIS}

O presente artigo tinha como objetivo verificar as práticas metodológicas dos pesquisadores brasileiros, em estudos em estratégia organizacional, tendo como base os artigos apresentados no EnANPAD 2007, 2008, 2009 e 2010 .

Por meio de criteriosa prospecção das principais características da pesquisa nesse campo de estudo, percebeu-se que a área de estudos em estratégia pode ser considerada em evolução com relação à complexidade metodológica. Paralelamente a essa evolução, parece existir uma iniciação de consolidação metodológica, bem como da própria área, com 
o passar dos anos. Esse fato é observado pelo número de trabalhados apresentados na área. Tais fatos vão ao encontro de outras pesquisas que analisam a academia brasileira na área tais como Jabbour, Santos e Barbieri (2008), Bertero, Caldas e Wood Jr. (1999), Bertero e Keinert (1994), corroborando-as.

Considerando a evolução da área ora pesquisada, pode-se perceber que alguns temas tenham tido mais ênfase no transcorrer dos anos, com destaque para área de Estratégia Competitiva e Corporativa, que teve um aumento de mais de $100 \%$ do ano de 2009 para 2010 no número de artigos analisados. Tal aumento pode estar relacionado ao aumento da importância da área para os estudos organizacionais devido ao momento vivido pelas organizações brasileiras em um contexto de retomada do crescimento econômico pós-crise econômica mundial. Em contraponto a isso, outras áreas sofreram impactos negativos no ano de 2010 em relação ao período anterior analisado, como é o caso do tema Gestão Internacional, que apresentou em 2009 quatro artigos e em 2010 nenhum artigo com critérios para análise.

Outro ponto levantado pela presente pesquisa é o predomínio do perfil qualitativo dos estudos em estratégia, que totalizaram $61,65 \%$ da amostra estudada, contra $31,07 \%$ de artigos com abordagem quantitativa e $7,28 \%$ com métodos mistos. Este resultado poderia sinalizar que os pesquisadores brasileiros desta área privilegiam um caminho metodológico, que prioriza o aprofundamento conceitual. Uma explicação possível também é a falta de abertura por parte das organizações para que os pesquisadores tenham acessos aos dados, que possibilitem uma investigação abrangente.

Com o estudo ora apresentado é possível verificar ainda que por ter a academia um viés qualitativo, faz uso, em sua maioria de dados primários $(50,49 \%)$ e ainda utiliza fortemente o questionário e as entrevistas como os instrumentos de coleta de dados que mais ocorrem, acontecendo em aproximadamente 43,68\% dos artigos analisados.

Outro ponto interessante a ser verificado é a questão da tipologia das pesquisas apresentadas nos trabalhos analisados, onde 68\% apresentam-se como explicativas ou descritivas, contra apenas $30 \%$ de estudos exploratórios. Percebe-se, quanto aos tipos de pesquisa adotados, o reforço da hipótese anteriormente levantada de que o estudo da estratégia no Brasil, apesar de ter avançado, ainda não atingiu o estágio de amadurecimento necessário para construir metodologia ou desenvolver teorias. Os estudos nacionais ainda estão fortemente influenciados pelo 
que é utilizado fora do país e são importados e adaptados às pesquisas em empresas brasileiras.

Portanto, pode-se concluir que a pesquisa em estratégia no Brasil apresenta-se em uma fase de expansão e de busca de uma identidade própria. Percebe-se ainda que estudos quantitativos, apesar de menor quantidade na atualidade, aumentaram gradativamente nos anos pesquisados. Também é possível afirmar que pesquisas do tipo exploratórias e descritivas também têm sido construídas de forma mais regular.

Por fim, é importante salientar que possíveis limitações da pesquisa ocorreram nas dificuldades encontradas para as delimitações, por vezes não claras, nos procedimentos metodológicos. Cuidados específicos foram tomados para a sua minimização, por meio da busca de categorias de análise, que pudessem expressar adequadamente a realidade observada e o uso de múltiplas fontes de dados, com triangulação para a sua rigorosa confirmação. Limitações analíticas também podem ter ocorrido em função da escolha amostral adotada nesse artigo.

No futuro, novos trabalhos poderão ser realizados com base na estrutura criada nesta pesquisa, o que auxiliará o maior entendimento das questões metodológicas utilizadas em pesquisa em estratégia. Também se sugere o desafio de explicar os fenômenos apresentados de forma analítica, propondo um diálogo aprofundado trans-paradigmático. Futuras pesquisas poderão verificar a relação interinstitucional entre os autores do campo, quantificando sua produção e, assim, analisar possíveis relações entre coautoria, produtividade e prestígio desses autores.

\section{REFERÊNCIAS}

ANPAD. Associação Nacional de Pós-Graduação e Pesquisa em Administração, 2011. Disponível em: <www.anpad.org.br>. Acesso em: 10/01/2011.

BARATA, R. B.; GOLDBAUM, M. Perfil dos pesquisadores com bolsa de produtividade em pesquisa do $\mathrm{CNPq}$ da área de saúde coletiva. Cadernos de Saúde Pública, v. 19, n. 6, p. 1863-1876, 2003.

BERTERO, C. O.; KEINERT, T. M. M. A evolução da análise organizacional no Brasil (1961-93). Revista de Administração de Empresas, v. 36, n.3, p. 81-90, 1994. 
BERTERO, C. O.; CALDAS, M. P. ; WOOD JR., T. Produção científica em administração de empresas: provocações, insinuações e contribuições para um debate local. Revista de Administração Contemporânea, v. 3, n. 1, p.147-178, 1999.

BULGACOV, S.; SOUZA, Q. R.; PROHMANN, J. I. DE P.; COSER, C.; BARANIUK, J. Administração estratégica: teoria e prática. São Paulo: Atlas, 2007.

CASSOL, N. K.; SILVEIRA, A.; HOELTGEBAUM, M.

Empreendedorismo Feminino: Análise da Produção Científica da Base de Dados do Institute for Scientific Information (ISI), 1997-2006. In:

ENCONTRO NACIONAL DA ASSOCIAÇÃO DOS PROGRAMAS DE PÓS-GRADUAÇÃO E PESQUISA EM ADMINISTRAÇÃO, 31., 2007, Rio de Janeiro. Anais... Rio de Janeiro, 2007.

CRESWELL, J. C. Projeto de Pesquisa: métodos qualitativo, quantitativo e misto.2.ed. Porto Alegre: Artmed, 2007.

FLICK, U. Uma introdução à pesquisa qualitativa. 2.ed. Porto Alegre: Bookman, 2004.

GIL, A. C. Como elaborar projetos de pesquisa. 3.ed. São Paulo: Atlas, 1996.

GODOI, C. K.; BANDEIRA-DE-MELLO, R. ; SILVA, A. B. Pesquisa qualitativa e o debate sobre a propriedade de pesquisar. In. GODOI, C. K., BANDEIRA-DE-MELLO, R; SILVA, A. B. Pesquisa qualitativa em estudos organizacionais: paradigmas, estratégias e métodos. São Paulo: Saraiva, 2006.

GODOY, A. S. Introdução à pesquisa qualitativa e suas possibilidades. Revista de Administração de Empresas, v. 35, n. 2, p. 57-63, 1995.

GOMES, C. A. S.; CORRÊA, D. M. M. C.; DOMINGOS, S. R. M. Participação Feminina na Produção Científica em Contabilidade publicada nos Anais dos Eventos ENANPAD, Congresso USP de Controladoria e Contabilidade e Congresso ANPCONT. In: ENCONTRO NACIONAL DA ASSOCIAÇÃO DOS PROGRAMAS DE PÓSGRADUAÇÃO E PESQUISA EM ADMINISTRAÇÃO, 34., 2010, Rio de Janeiro. Anais... Rio de Janeiro, 2010.

HAIR, JR. J. F.; BABIN, B.; MONEY, A. H. E SAMOUEL P. Fundamentos de Métodos de Pesquisa em Administração. Porto Alegre: Bookman, 2005. 
JABBOUR, C J.; SANTOS, F. C. A.; BARBIERI, J. C. Gestão Ambiental Empresarial: um Levantamento da Produção Científica Brasileira Divulgada em Periódicos da Área de Administração entre 1996 e 2005. Revista de Administração Contemporânea, v.12, n. 3, p.689-715, 2008.

LEITE FILHO, G. A. Perfil da Produção Científica dos Docentes e Programas de Pós-Graduação em Ciências Contábeis no Brasil. In: ENCONTRO NACIONAL DA ASSOCIAÇÃO DOS PROGRAMAS DE PÓS-GRADUAÇÃO E PESQUISA EM ADMINISTRAÇÃO, 33., 2009, São Paulo. Anais... São Paulo, 2009.

MACHADO-DA-SILVA, C. L.; CUNHA, V. C. DA; AMBONI, N. Organizações: o estado da arte da produção acadêmica no Brasil. In: ENCONTRO NACIONAL DA ASSOCIAÇÃO DOS PROGRAMAS DE PÓS-GRADUAÇÃO E PESQUISA EM ADMINISTRAÇÃO, 14., 1990. Florianópolis. Anais... Florianópolis, 1990.

MALHOTRA, N.K. Pesquisa de marketing: Uma orientação aplicada. 4. ed. Porto Alegre: Bookman, 2006.

MATURANA, M. T. I. Guía para la preparación de resúmenes. Serie Bibliotecología y Gestión de Información, v. 41, p.1-24, 2008.

MAY, T. Pesquisa social: questões, métodos e processos. 3.ed. Porto Alegre: Artmed, 2004.

MELI, D. B. Reflexões Sobre a Configuração da Pesquisa Contábil Sob a Óptica das Redes no Período 2004-2008: Um Estudo nos Periódicos Nacionais. In: ENCONTRO NACIONAL DA ASSOCIAÇÃO DOS PROGRAMAS DE PÓS-GRADUAÇÃO E PESQUISA EM ADMINISTRAÇÃO, 34., 2010. Rio de Janeiro, Anais... Rio de Janeiro, 2010.

MINAYO, M. C. S. Ciência, técnica e arte: o desafio da pesquisa social. In: MINAYO, M.C.S. Pesquisa social: teoria, método e criatividade. Petrópolis: Vozes, 1994.

MINTZBERG, H; AHLSTRAND, B.E.; LAMPEL, J. Safári de Estratégia: um roteiro pela selva do planejamento estratégico. Porto Alegre: Bookman, 2000.

MORIKI, A.M.N.; MARTINS, G.A. Análise do Referencial Bibliográfico de Teses e Dissertações sobre Contabilidade e Controladoria. In: CONGRESSO USP DE CONTROLADORIA E CONTABILIDADE, 3. 2003. Anais... São Paulo, 2003. 
NASSIF, V. M. J.; SILVA, N. B DA; ONO, A. T. ; BONTEMPO, P. C. Empreendedorismo: Área em Evolução? Uma Revisão dos Estudos e Artigos Publicados entre 2001 e 2008. In: ENCONTRO NACIONAL DA ASSOCIAÇÃO DOS PROGRAMAS DE PÓS-GRADUAÇÃO E PESQUISA EM ADMINISTRAÇÃO, 33., 2009. Anais... São Paulo, 2009.

PETTIGREW, A.M. The Character and Significance of Strategy Process Research. Strategic Management Journal, v.13, n. 1, p.5-16, 1992.

PREARO, L. C.; ROMEIRO, M. DO C. Avaliação do emprego da técnica de modelagem de equações estruturais em teses e dissertações de algumas instituições de ensino superior. In: ENCONTRO NACIONAL DA ASSOCIAÇÃO DOS PROGRAMAS DE PÓS-GRADUAÇÃO E PESQUISA EM ADMINISTRAÇÃO, 34., 2010. Anais... Rio de Janeiro, 2010.

RICHARDSON, R. J. Pesquisa Social: métodos e técnicas. 3.ed. São Paulo: Atlas, 1985.

SILVA, E. L. D.A.; MENEZES, E. M.; PINHEIRO, L. V. Avaliação da produtividade científica dos pesquisadores nas áreas de ciências humanas e sociais aplicadas. Informação e Sociedade, v.13, n. 2, p.193-222, 2003.

TRIVIÑOS, A. N. S. Introdução à pesquisa em ciências sociais: a pesquisa qualitativa em educação. São Paulo: Atlas.

VERGARA, S. C. Projetos e relatórios de pesquisa em administração. São Paulo: Atlas, 2000.

WALTER, S. A.; LANZA, B.B.B.; SATO, K. H.; SILVA, E. D.A.; BACH, T. M. Análise da Produção Científica de 1997 a 2009 na Área de Estratégia: Produção e Continuidade de Atores e Cooperação entre Instituições Brasileiras e Estrangeiras. In: ENCONTRO NACIONAL DA ASSOCIAÇÃO DOS PROGRAMAS DE PÓS-GRADUAÇÃO E PESQUISA EM ADMINISTRAÇÃO, 34., 2010. Anais... Rio de Janeiro, 2010. 


\section{DADOS DOS AUTORES}

JULIO ERNESTo Colla (juliocolla@gmail.com)

Doutorando em Administração pela PPAD/PUCPR

Instituição de vinculação: Universidade Estadual do Norte do Paraná Campus Paranavaí

Paranavaí/PR - Brasil

Áreas de interesse em pesquisa: Estratégia e Práticas Estratégicas.

JÚlio Adriano FERREIRA dOS REIS (julio.reis@ @ pucpr.br)

Doutorando em Administração pela PPAD/PUCPR

Instituição de vinculação: Pontifícia Universidade Católica do Paraná Curitiba/PR - Brasil

Áreas de interesse em pesquisa: Estratégia empresarial, Gestão de Pessoas e Complexidade organizacional.

HEITOR TAKASHI KATO (heitor.kato@gmail.com)

Doutor em Administração pela FGV-EAESP

Instituição de vinculação: Pontifícia Universidade Católica do Paraná

Curitiba/PR - Brasil

Áreas de interesse em pesquisa: Estratégia, Serviços, Varejo e Marketing.

Recebido em: 27/03/2011 • Aprovado em: 19/06/2011 